\title{
Induction machine behavioral modeling for prediction of EMI propagation
}

\author{
M. TURZYŃSKI* \\ Faculty of Electrical and Control Engineering, Gdańsk University of Technology, 11/12 Narutowicza St., 80-233 Gdańsk, Poland
}

\begin{abstract}
This paper presents the results of wideband behavioral modeling of an induction machine (IM). The proposed solution enables modeling the IM differential- and common-mode impedance for a frequency range from $1 \mathrm{kHz}$ to $10 \mathrm{MHz}$. Methods of parameter extraction are derived from the measured IM impedances. The developed models of $1.5 \mathrm{~kW}$ and $7.5 \mathrm{~kW}$ induction machines are designed using the Saber Sketch scheme editor and simulated in the SABER simulator. Modeling validation is based on prediction of electromagnetic interference (EMI) emissions of common-mode and differential-mode current spectra of experimental inverter-fed IM drives.
\end{abstract}

Key words: circuit simulation, wideband modeling, inverter-fed IM model, EMI prediction.

\section{Introduction}

The induction machine (IM) is the most frequently used machine in electric drives. Nowadays, it is usually fed by hard-switched inverters. The transistor switching affects levels of disturbances which can be evaluated by measuring common- and differential-mode currents [1-3]. Flow of these currents causes many negative effects, including permanent damage to devices. For example, a common-mode current on the machine side is responsible for the appearance of electric discharge machining (EDM) currents, which lead to premature damage of the machine bearing races [4]. Proper identification of electromagnetic interference (EMI) propagation paths and the mechanism of their generation enables the application of equivalent countermeasures [5].

Accurate modeling and simulation may be efficient for EMI emission assessment, before a physical prototype of a drive is completed [6]. This type of simulation requires wideband models to ensure sufficient accuracy in a range of frequency - up to few tens of $\mathrm{MHz}$ [7]. High accuracy requirements enforce the use of complex models, which are often described by non-linear equations [8].

However, the necessity of calculation of a number of parameters with the procedures of their extraction is one of the most important limitations. This is observed especially in the wideband modeling of electric drives fed by power converters when advanced models of power semiconductors, passive components, PCB paths, conductors or electrical machines have to be used $[9,10]$. It should be noted that the complication of inverter models increases rapidly for topologies, e.g. multi levels or resonant converters possessing a large number of transistor switches. Then, the simulation process becomes time-consuming and often cannot be successfully finished due to numerical problems. Therefore, a trade-off between the accuracy and complexity is the crucial issue of model optimization [8].

\footnotetext{
*e-mail: marek.turzynski@pg.gda.pl
}

Most IM models dedicated for EMC analysis have been developed from the phase-belt winding model considered by Zhong et al. in [11]. This model includes winding leakage inductances, ground capacitive couplings, and the capacitances between coils. Further enhancement in [12] includes stator and rotor resistances, and resistances for eddy currents circuit representation. However, modeling results from $[11,12]$ allow to reflect only the basic shape of the common- and differential-mode IM impedance frequency characteristics. Due to differences in values of winding inductance for common- and differential-mode operation for frequencies below $100 \mathrm{kHz}$, the model has to be parameterized every time, depending on the type of analysis. An exemplary solution of this problem is shown in [13, 14], where the additional mutual inductances between machine windings were considered. Despite the fact that the models' accuracy is reported high for frequencies up to $100 \mathrm{MHz}$, their topology is complex and the procedures of parameter extraction may be problematic.

An interesting modeling approach has been presented in the series of papers [15-18], where a high-frequency equivalent circuit of the real coil has been used to develop a wideband model of induction machine windings. The topology of this model is less complicated than that of the model presented in [14], however, additional mutual inductances between machine windings for different phases are included. The extraction procedure of model parameters may be difficult in case of some parameters, e.g. the series model resistances. Moreover, additional measurements of machine stator windings are needed to extract the values of mutual inductances. Model accuracy is reported for frequencies up to $10 \mathrm{MHz}$.

Another approach is proposed in [7], where the machine impedance is modeled using the equivalent circuit including the skin effect [19]. The model accuracy is satisfactory, but the resonance frequency $f_{r 5}$, which is present in the differential-mode impedance characteristics (Fig. 3), has not been reported. The model parameters are also difficult to evaluate, because resolution algorithms of nonlinear systems have to be used. 
The solution proposed in this paper is based on the behavioral modeling approach. It means that the model reflects the behavior of a device, without the analysis of its physical phenomena. This approach enables a reduction of model complexity, without a significant decrease of its accuracy [8].

The main contribution of the paper is the unified behavioral wideband IM model, which enables to predict common-mode $(\mathrm{CM})$ and differential-mode (DM) machine impedance for frequencies up to $10 \mathrm{MHz}$. The considered model is a lumped parameter model with a reduced number of linear components. Parameter identification is based on measurable IM impedance characteristics. The model has been implemented in the SABER simulator and validated by a comparison of simulation and experimental results.

\section{CM and DM impedances}

The configuration of the measurement setup applied to obtain induction machine CM and DM impedance frequency characteristics has been shown in Fig. 1. To achieve correctness of the measurement, an impedance analyzer fed by isolation transformer was required. It was checked that in the analyzed range of frequency $(1 \mathrm{kHz}-10 \mathrm{MHz}), \mathrm{IM}$ impedance characteristics are independent of the angular velocity of the rotor.

a)

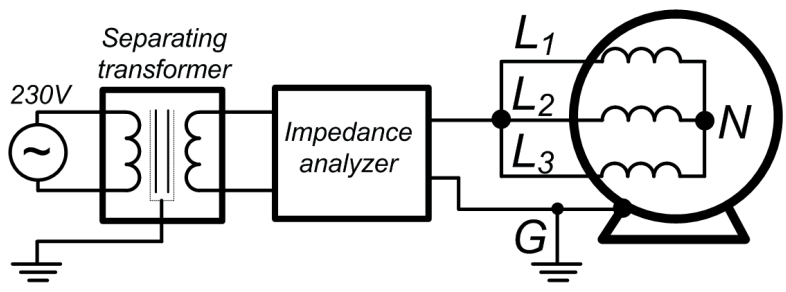

b)

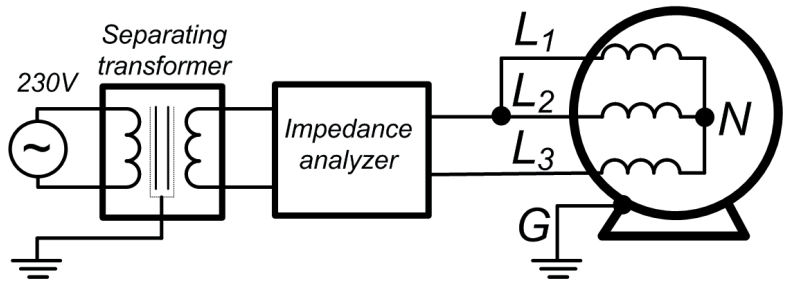

Fig. 1. Measurement setup: a) common-mode impedance, b) differential mode impedance

The typical characteristic of an induction machine common-mode impedance $Z_{c}(f)$ is presented in Fig. 2. It is measured between input windings terminals, which are connected to each other and the grounded case terminal [7] (Fig. 1a). The impact of capacitive elements is evident for almost all considered domains, except for the distinguished frequency bands B and $\mathrm{F}$, indicating inductive components.

An induction machine differential-mode impedance $Z_{d}$ is measured between one phase and two other parallel-connected phases [14] (Fig. 1b). Typical characteristic of $Z_{d}(f)$ is presented in Fig. 3. The influence of machine inductances is noticeable

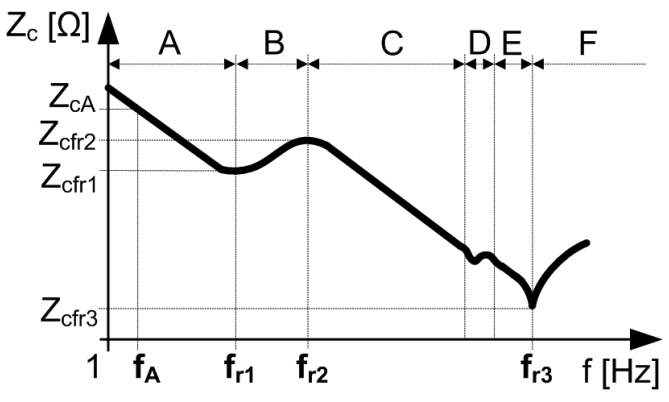

Fig. 2. IM common-mode impedance

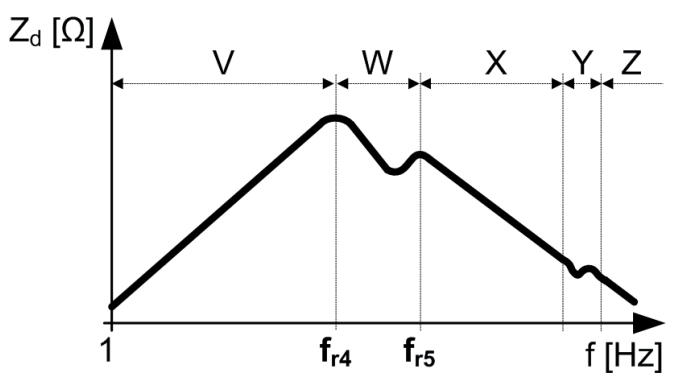

Fig. 3. IM differential-mode impedance

for frequencies lower than resonant frequency $f_{r 4}$. The impact of capacitive elements is observed for frequencies higher than $f_{r 4}$.

\section{High frequency impedance model}

A topology of IM unified model for a common- and differential-mode analysis has been presented in Fig. 4. The proposed

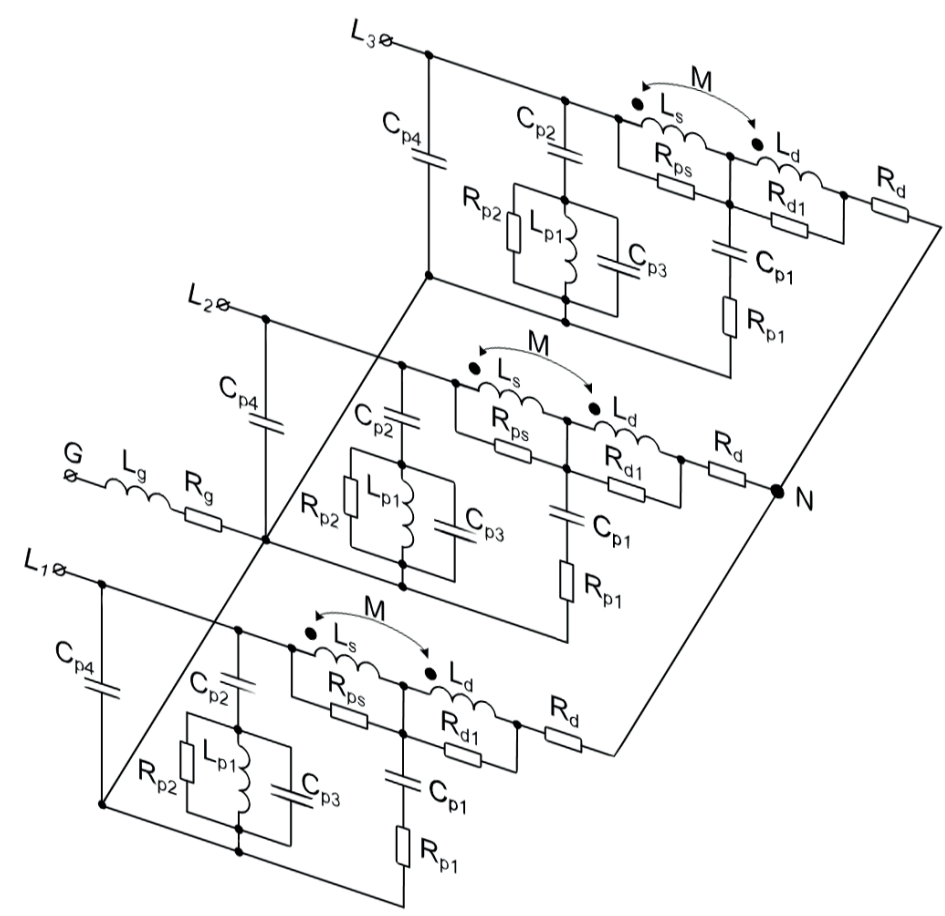

Fig. 4. Induction machine $\mathrm{CM}$ and $\mathrm{DM}$ impedance behavioral model 
behavioral model of a three-phase IM provides both commonand differential-mode impedances. In this model: $\mathrm{L}_{1}, \mathrm{~L}_{2}$, and $\mathrm{L}_{3}$ are input terminals of machine phase windings, $\mathrm{N}$ is a neutral point, and $\mathrm{G}$ is the grounded case terminal.

3.1. Common-mode impedance. For $f>>f_{r 3}$ (section $F$ in Fig. 2), impedance $Z_{c}$ has an inductive character and it is shaped by the resistance $\mathrm{R}_{\mathrm{g}}$ and inductance $\mathrm{L}_{\mathrm{g}}$ :

$$
\overline{Z_{c}(j \omega)}=R_{g}+j \omega L_{g},
$$

where $\omega=2 \pi f$.

The series resonance between $\mathrm{L}_{\mathrm{g}}$ and capacitances $\mathrm{C}_{\mathrm{p} 2}, \mathrm{C}_{\mathrm{p} 3}$, and $\mathrm{C}_{\mathrm{p} 4}$ is observed for $\mathrm{f}=\mathrm{f}_{\mathrm{r} 3}$, so it can be assumed that

$$
f_{r 3}=\frac{1}{2 \pi \sqrt{3 \cdot L_{g} \cdot \frac{C_{p 2} C_{p 3}+C_{p 2} C_{p 4}+C_{p 3} C_{p 4}}{C_{p 2}+C_{p 3}}}},
$$

and then

$$
\left|Z_{c}\left(f_{r 3}\right)\right|=Z_{c f r 3}=R_{g}
$$

In section $\mathrm{E}$ the impedance $\mathrm{Z}_{\mathrm{c}}$ is dominated by a parallel connection of capacitance $\mathrm{C}_{\mathrm{p} 4}$ with, connected in series, capacitances $\mathrm{C}_{\mathrm{p} 3}$ and $\mathrm{C}_{\mathrm{p} 2}$. Hence, the common-mode impedance of the machine is described by

$$
\left|Z_{c}(\omega)\right|=\frac{C_{p 2}+C_{p 3}}{3 \varpi\left(C_{p 2} C_{p 3}+C_{p 2} C_{p 4}+C_{p 3} C_{p 4}\right)},
$$

and similarly, in section $\mathrm{C}$, by

$$
\left|Z_{c}(\omega)\right|=\frac{1}{3 \omega\left(C_{p 2}+C_{p 4}\right)} .
$$

Series and parallel resonances between inductance $\mathrm{L}_{\mathrm{p} 1}$ and capacitances $\mathrm{C}_{\mathrm{p} 2}$ and $\mathrm{C}_{\mathrm{p} 3}$ are noticed in section D. Hence, neglecting the impact of $\mathrm{R}_{\mathrm{g}}$ and $\mathrm{L}_{\mathrm{g}}$, it can be assumed that the common-mode machine impedance in sections $\mathrm{C}, \mathrm{D}$, and $\mathrm{E}$ is described as follows:

$$
\begin{aligned}
& \overline{Z_{c}(j \omega)}= \\
& =\frac{1}{3} \frac{1}{j \omega C_{p 4}+\frac{1}{\frac{1}{\frac{1}{R_{p 2}}+j\left(\omega C_{p 3}-\frac{1}{\omega L_{p 1}}\right)}+\frac{1}{j \omega C_{p 2}}}} .
\end{aligned}
$$

For frequency $\mathrm{f}<<\mathrm{f}_{\mathrm{r} 1}$ in section $\mathrm{A}$, the impedance $Z_{c}$ is dominated by a parallel connection of capacitances $\mathrm{C}_{\mathrm{p} 1}, \mathrm{C}_{\mathrm{p} 2}$, and $\mathrm{C}_{\mathrm{p} 4}$ :

$$
\left|Z_{c}(\omega)\right|=\frac{1}{3 \omega \cdot\left(C_{p 1}+C_{p 2}+C_{p 4}\right)} .
$$

On the boundary between sections $\mathrm{A}$ and $\mathrm{B}$, the series resonance between $\mathrm{C}_{\mathrm{p} 1}$ and $\mathrm{L}_{\mathrm{s}}$ is observed for $\mathrm{f}=\mathrm{f}_{\mathrm{r} 1}$, so it can be assumed that

$$
f_{r 1} \approx \frac{1}{2 \pi \sqrt{L_{s} \cdot C_{p 1}}}
$$

and similarly, when the frequency $f$ equals to $\mathrm{f}_{\mathrm{r} 2}$, the parallel resonance between components $\mathrm{L}_{\mathrm{s}}, \mathrm{C}_{\mathrm{p} 2}$, and $\mathrm{C}_{\mathrm{p} 4}$ is noted. Finally, the common-mode impedance $\mathrm{Z}_{\mathrm{c}}$ in sections $\mathrm{A}$ and $\mathrm{B}$ is described by the following equation:

$$
\overline{Z_{c}(j \omega)}=\frac{1}{3} \cdot \frac{1}{j \omega C_{p x}+\overline{Y_{c 1}(j \omega)}},
$$

where

$$
C_{p x}=C_{p 2}+C_{p 4}
$$

and

$$
\begin{aligned}
& \overline{Y_{c 1}(j \omega)}= \\
& =\frac{C_{p 1} \cdot\left(j \omega R_{p s}-\omega^{2} L_{s}\right)}{R_{p s}+j \omega L_{s}-\omega C_{p 1}\left(\varpi L_{s} R_{p 1}-\varpi L_{s} R_{p s}+j R_{p 1} R_{p s}\right)} .
\end{aligned}
$$

3.2. Differential-mode impedance. For frequency $f>>f_{r 5}$ in sections X, Y, and Z (Fig. 3), the differential-mode impedance characteristic $Z_{d}(f)$ is shaped in the same way as for the common-mode impedance in sections $\mathrm{C}, \mathrm{D}$, and $\mathrm{E}$ in (6). Hence, the differential-mode impedance is expressed by:

$$
\begin{aligned}
& \overline{Z_{d}(j \omega)}= \\
& =\frac{3}{2} \frac{1}{j \omega C_{p 4}+\frac{1}{\frac{1}{\frac{1}{R_{p 2}}+j\left(\omega C_{p 3}-\frac{1}{\omega L_{p 1}}\right)}+\frac{1}{j \omega C_{p 2}}}} .
\end{aligned}
$$

In sections $\mathrm{V}$ and $\mathrm{W}$, an influence of $\mathrm{L}_{\mathrm{d}}, \mathrm{L}_{\mathrm{s}}$, and $\mathrm{M}$ is noted. Neglecting the impact of resistances $R_{d}, R_{p 1}$, and $R_{p 2}$, the differential-mode impedance is then determined by parallel connection of capacitances $\mathrm{C}_{\mathrm{p} 4}$ and $\mathrm{C}_{\mathrm{p} 2}$ with impedance $\mathrm{Z}_{\mathrm{dx}}$ :

$$
\overline{Z_{d}(j \omega)}=\frac{3}{2} \cdot \frac{\overline{Z_{d x}(j \omega)}}{\left.1+j \omega\left(C_{p 2}+C_{p 4}\right) \cdot C_{p 3} C_{p 4}\right) \overline{Z_{d x}(j \omega)}}
$$

Impedance $Z_{d x}$ is dependent from capacitance $C_{p 1}$, resistances $\mathrm{R}_{\mathrm{ps}}$ and $\mathrm{R}_{\mathrm{d} 1}$, inductances $\mathrm{L}_{\mathrm{d}}$ and $\mathrm{L}_{\mathrm{s}}$, and the mutual inductance $\mathrm{M}$, and it is calculated using the following set of expressions:

$$
\overline{Z_{d x}(j \omega)}=\frac{\left(Z_{1}-j \omega Z_{2}\right)\left(Z_{3}+j \omega Z_{4}\right)}{Z_{1}^{2}+\left(\omega Z_{2}\right)^{2}},
$$


where

$$
\begin{aligned}
Z_{1} & =R_{p s}\left(\omega^{2} L_{d} L_{s}-\omega^{2} M^{2}-R_{p s} R_{d 1}+\omega^{2} R_{p s} R_{d 1} L_{d} C_{p 1}\right), \\
Z_{2} & =R_{p s}\left(\omega^{2} R_{d 1} L_{s} L_{d} C_{p 1}-\omega^{2} R_{d 1} M^{2} C_{p 1}-\right. \\
& \left.-L_{s} R_{d 1}-L_{d 1} R_{p s}\right), \\
Z_{3} & =R_{p s} \omega^{2}\left(L_{s} L_{d}-M^{2}\right)\left(R_{d 1}+R_{p s}\right), \\
Z_{4} & =R_{p s}{ }^{2} R_{d 1}\left(\omega^{2} L_{s} L_{d} C_{p 1}-\omega^{2} M^{2} C_{p 1}-2 M-L_{s}-L_{d}\right) .
\end{aligned}
$$

On the boundary between sections $\mathrm{V}$ and $\mathrm{W}$ for $\mathrm{f}=\mathrm{f}_{\mathrm{r} 4}$, the parallel resonance between $\mathrm{C}_{\mathrm{p} 1}$ and $\mathrm{L}_{\mathrm{d}}$ is observed:

$$
f_{r 4} \approx \frac{1}{2 \pi \sqrt{L_{d} \cdot C_{p 1}}}
$$

If $\mathrm{f}<<\mathrm{f}_{\mathrm{r} 4}$, the $\mathrm{Z}_{\mathrm{d}}(\mathrm{f})$ characteristic is shaped by a series connection of resistance $R_{d}$ with inductances $L_{s}$ and $L_{d}$ and mutual inductance $M$ (per each phase). The influence of other model components is neglected, and the differential mode impedance is calculated according to the following formula:

$$
\overline{Z_{d}(j \omega)}=\frac{3}{2}\left[R_{d}+j \omega\left(L_{d}+L_{s}+2 M\right)\right] .
$$

3.3. Procedure of parameter extraction. The method of parameter extraction is based on measurable common- and differential-mode impedance machine characteristics. In the first step, the values of capacitances $\mathrm{C}_{\mathrm{p} 2}, \mathrm{C}_{\mathrm{p} 3}, \mathrm{C}_{\mathrm{p} 4}$, the inductance $\mathrm{L}_{\mathrm{p} 1}$, and the resistance $\mathrm{R}_{\mathrm{p} 2}$ have been obtained. Neglecting the impact of $\mathrm{R}_{\mathrm{g}}$ and $\mathrm{L}_{\mathrm{g}}$, the absolute value of the common-mode impedance in sections $\mathrm{C}, \mathrm{D}$, and $\mathrm{E}$ has been evaluated from (6):

$$
Z_{c}(\omega)=\frac{1}{3} \cdot \sqrt{\frac{Z_{A}^{2}+Z_{B}^{2}}{\left(\omega C_{p 4}\right)^{2}\left(Z_{A}^{2}+Z_{B}^{2}\right)-2 \omega C_{p 4} Z_{B}+1}}
$$

where

$$
\begin{gathered}
Z_{A}=\frac{1}{R_{p 2}\left(\frac{1}{R_{p 2}^{2}}+\frac{\left(\omega^{2} L_{p 1} C_{p 3}-1\right)^{2}}{\left(\omega L_{p 1}\right)^{2}}\right)}, \\
Z_{B}=-\frac{1}{\omega C_{p 2}}-\frac{\omega^{2} L_{p 1} C_{p 3}-1}{\omega L_{p 1}\left(\frac{1}{R_{p 2}^{2}}+\frac{\left(\omega^{2} L_{p 1} C_{p 3}-1\right)^{2}}{\left(\omega L_{p 1}\right)^{2}}\right)} .
\end{gathered}
$$

Parameters $\mathrm{C}_{\mathrm{p} 2}, \mathrm{C}_{\mathrm{p} 3}, \mathrm{C}_{\mathrm{p} 4}, \mathrm{~L}_{\mathrm{p} 1}$, and $\mathrm{R}_{\mathrm{p} 2}$ in (18-20) have been identified from the measured $\mathrm{Z}_{\mathrm{c}}(\omega)$ characteristic in sections $\mathrm{C}$, $\mathrm{D}$, and $\mathrm{E}$ by the curve fitting method using fminsearch function of MATLAB/OCTAVE $[20,21]$ programs using the sum of squared errors criterion of fitting. Next, $R_{g}$ and $L_{\mathrm{g}}$ have been calculated by converting (2) and (3):

$$
\begin{gathered}
L_{g}=\frac{C_{p 2}+C_{p 3}}{4 \pi^{2} f_{r 3}^{2}\left(C_{p 2} C_{p 3}+C_{p 2} C_{p 4}+C_{p 3} C_{p 4}\right)}, \\
R_{g}=Z_{c}\left(2 \pi f_{r 3}\right)=Z_{c f r 3} .
\end{gathered}
$$

The value of capacitance $C_{p 1}$ can be obtained from (7):

$$
C_{p 1}=\frac{1}{6 \pi f_{A} Z_{c A}}-C_{p 2}-C_{p 4}
$$

where $\mathrm{Z}_{\mathrm{cA}}$ is an absolute value of the common-mode impedance for the frequency $f_{A}$ (Fig. 2). Next, the value of the inductance $\mathrm{L}_{\mathrm{S}}$ has been calculated:

$$
L_{s}=\frac{1}{4 \pi^{2} f_{r 1}^{2} C_{p 1}} .
$$

To find resistances $R_{p s}$ and $R_{p 1}$, the system of equations describing the value of common-mode impedance for resonant frequencies $\mathrm{fr}_{1}$ and $\mathrm{fr}_{2}$ has been calculated:

$$
\left\{\begin{array}{l}
Z_{c f r 1}=Z_{c}\left(\omega_{f r 1}\right)=\frac{\omega_{f r 1}{ }^{2} L_{s}^{2}\left(R_{p s}+R_{p 1}\right)+R_{p 1} R_{p s}^{2}}{3\left(\omega_{f r 1}{ }^{2} L_{s}^{2}+R_{p s}^{2}\right)} \\
Z_{c f r 2}=Z_{c}\left(\omega_{f r 2}\right)=\frac{\omega_{f r 2}{ }^{2} C_{p 1}{ }^{2} Z_{X}{ }^{2}+Z_{Z}^{2}}{3 \cdot \omega_{f r 2}{ }^{2} C_{p 1}{ }^{2} Z_{Y} Z_{X}} \\
Z_{X}=\omega_{f r 2}{ }^{2} L_{s}^{2}\left(R_{p s}+R_{p 1}\right)+R_{p 1} R_{p s} \\
Z_{Y}=\omega_{f r 2}{ }^{2} L_{s}^{2}+R_{p s}{ }^{2} \\
Z_{Z}=\omega_{f r 2}{ }^{2} L_{s}^{2}-\omega_{f r 2}{ }^{2} R_{p s}{ }^{2} L_{s} C_{p 1}+R_{p s}{ }^{2} \\
\omega_{f r 1}=2 \pi f_{r 1} \\
\omega_{f r 2}=2 \pi f_{r 2}
\end{array} .\right.
$$

Due to the complexity of the set of equations (25), a numerical method based on the Newton-Raphson algorithm has been used to extract values of $R_{p s}$ and $R_{p 1}$.

To complete the model parameters, the values of $\mathrm{L}_{\mathrm{d}}, \mathrm{R}_{\mathrm{d} 1}$, $M$, and $R_{d}$ have to be extracted. Neglecting the influence of resistances $R_{p 1}$ and $R_{d}$, the absolute value of differential-mode impedance $Z_{d}$ in sections $V$ and $W$ (Fig. 2) has been evaluated:

$$
Z_{d}(\varpi)=\frac{3}{2} \frac{\sqrt{\left[Z_{d 1}(\varpi)\right]^{2}+\left[\omega \cdot Z_{d 2}(\varpi)\right]^{2}}}{2 \omega^{2}\left(Z_{2}+C_{p x} Z_{3}\right)^{2}+\left(Z_{1}-\omega^{2} C_{p x} Z_{4}\right)^{2}},
$$

where

$$
Z_{d 1}(\varpi)=\omega^{2} Z_{2} Z_{4}+Z_{1} Z_{3}
$$

$$
Z_{d 2}(\varpi)=C_{p x} Z_{3}^{2}+Z_{2} Z_{3}+\omega^{2} C_{p x} Z_{4}^{2}-Z_{1} Z_{4}
$$

$\mathrm{C}_{\mathrm{px}}$ is defined by (10) and impedances $\mathrm{Z}_{1}, \mathrm{Z}_{2}, \mathrm{Z}_{3}$, and $\mathrm{Z}_{4}$ are described by (15). Similarly to the method of parameter extraction in equations (18-20), inductances $L_{d}, M$, and resis- 
tance $\mathrm{R}_{\mathrm{d} 1}$ in (15) and (26-28) have been evaluated using a fitting method based on the fminsearch function of MATLAB/ OCTAVE programs and measured points of the experimental $\mathrm{Z}_{\mathrm{d}}(\mathrm{f})$ characteristic in sections $\mathrm{V}$ and $\mathrm{W}$ (Fig. 3). The value of winding resistance $R_{d}$ has been measured experimentally by a measurement bridge.

\section{Simulation and experimental results}

The considered model has been validated for an IM of different power $-1.5 \mathrm{~kW}$ and $7.5 \mathrm{~kW}$. Measurement of impedance characteristics was carried out using a Keysight E4990A (20 Hz-20 MHz) impedance analyzer. The MT4090 LCR meter was used to obtain the winding resistance $R_{d}$. Model parameters have been estimated using the procedure described in Section 3. Next, the developed model has been designed using the SABER Sketch scheme editor and embedded into the library of the SABER simulator. Parameters for $1.5 \mathrm{~kW}$ and $7.5 \mathrm{~kW}$ induction machines are shown in Table 1.

Simulated and measured frequency characteristics of IM common- and differential-mode impedance were presented in Figs. 5 and 6. Inductive or capacitive character of simulated

a)

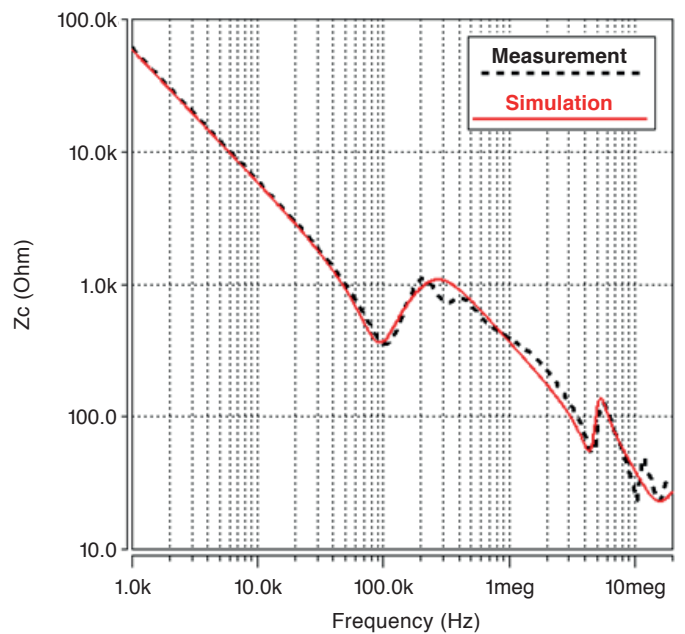

b)

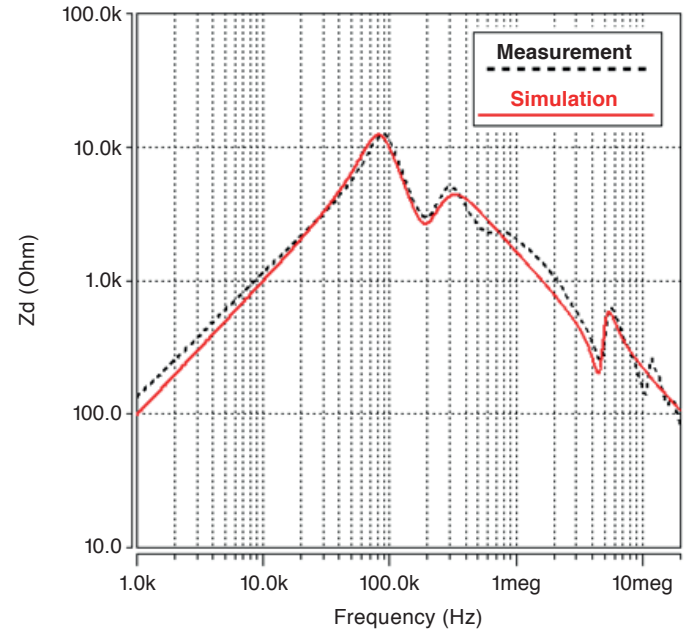

Table 1

An induction machine common- and differential- mode impedance model parameters

\begin{tabular}{|c|c|c|c|}
\hline \multirow{2}{*}{ Parameter } & \multicolumn{2}{|c|}{ Value } & \multirow{2}{*}{ Unit } \\
\cline { 2 - 3 } & $\mathbf{1 . 5} \mathbf{~ k W}$ & $\mathbf{7 . 5} \mathbf{~ k W}$ & \\
\hline $\mathrm{C}_{\mathrm{p} 1}$ & 0.750 & 1.31 & $\mathrm{nF}$ \\
\hline $\mathrm{C}_{\mathrm{p} 2}$ & 141 & 64 & $\mathrm{pF}$ \\
\hline $\mathrm{C}_{\mathrm{p} 3}$ & 500 & 0.102 & $\mathrm{nF}$ \\
\hline $\mathrm{C}_{\mathrm{p} 4}$ & 4.3 & 255 & $\mathrm{pF}$ \\
\hline $\mathrm{L}_{\mathrm{d}}$ & 3 & 7.2 & $\mathrm{mH}$ \\
\hline $\mathrm{L}_{\mathrm{g}}$ & 309 & 250 & $\mathrm{nH}$ \\
\hline $\mathrm{L}_{\mathrm{p} 1}$ & 1.86 & 23.9 & $\mu \mathrm{H}$ \\
\hline $\mathrm{L}_{\mathrm{s}}$ & 3.88 & 7.6 & $\mathrm{mH}$ \\
\hline $\mathrm{M}$ & 1.3 & 2.4 & $\mathrm{mH}$ \\
\hline $\mathrm{R}_{\mathrm{d}}$ & 2.9 & 1.77 & $\Omega$ \\
\hline $\mathrm{R}_{\mathrm{d} 1}$ & 4000 & 5230 & $\Omega$ \\
\hline $\mathrm{R}_{\mathrm{g}}$ & 22 & 5 & $\Omega$ \\
\hline $\mathrm{R}_{\mathrm{p} s}$ & 4700 & 6250 & $\Omega$ \\
\hline $\mathrm{R}_{\mathrm{p} 1}$ & 2.5 & 100 & $\Omega$ \\
\hline $\mathrm{R}_{\mathrm{p} 2}$ & 0.33 & 2.86 & $\mathrm{k} \Omega$ \\
\hline & & & \\
\hline
\end{tabular}
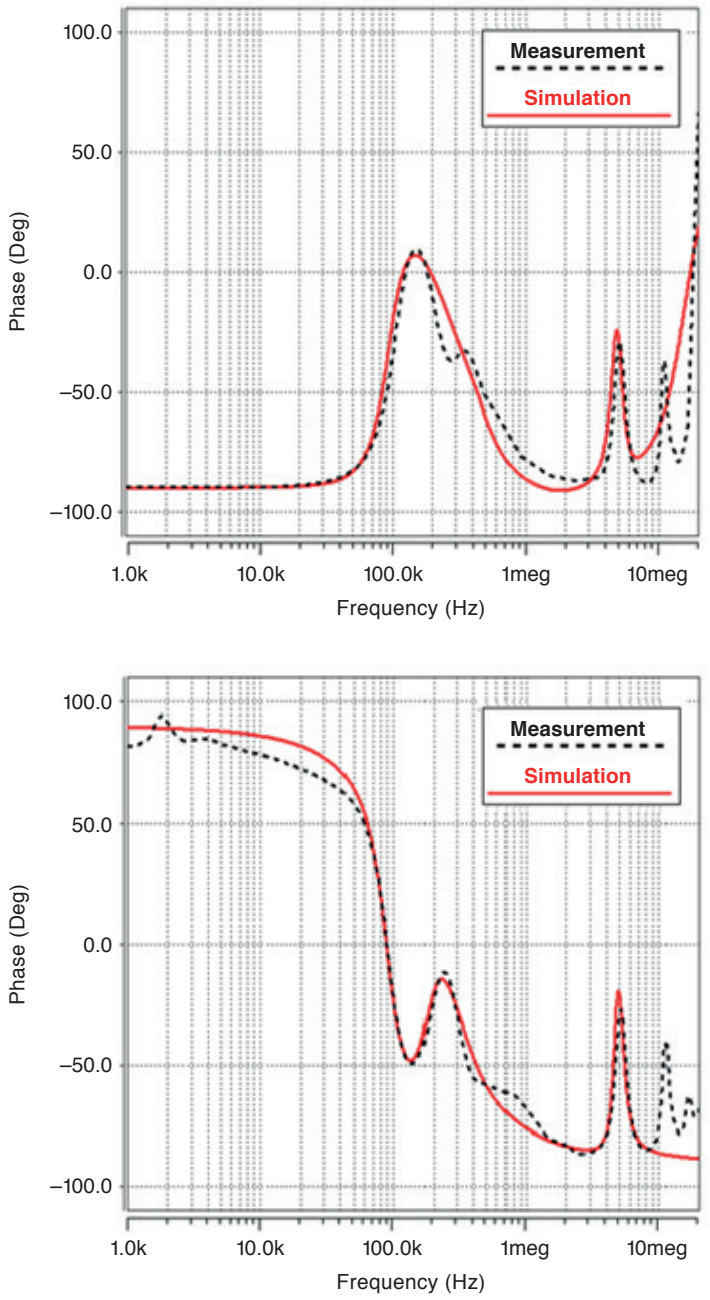

Fig. 5. Measurement and simulation of the $1.5 \mathrm{~kW}$ induction machine: a) common-mode impedance, b) differential-mode impedance 
a)

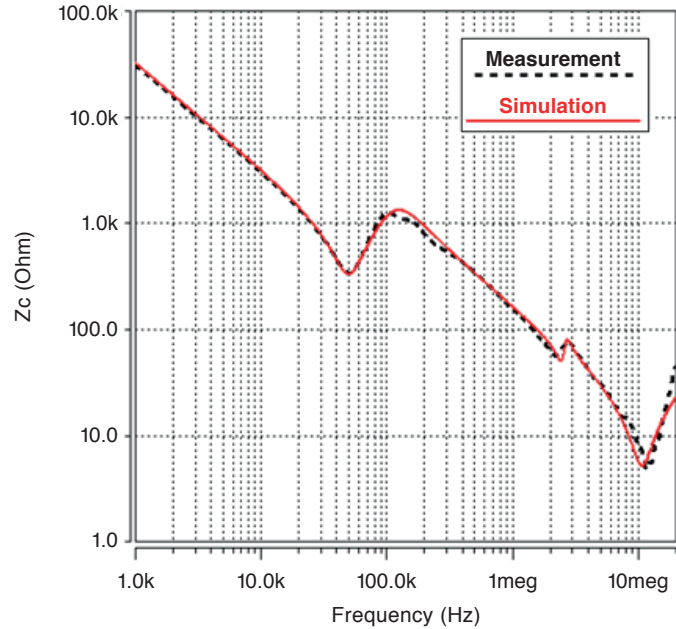

b)

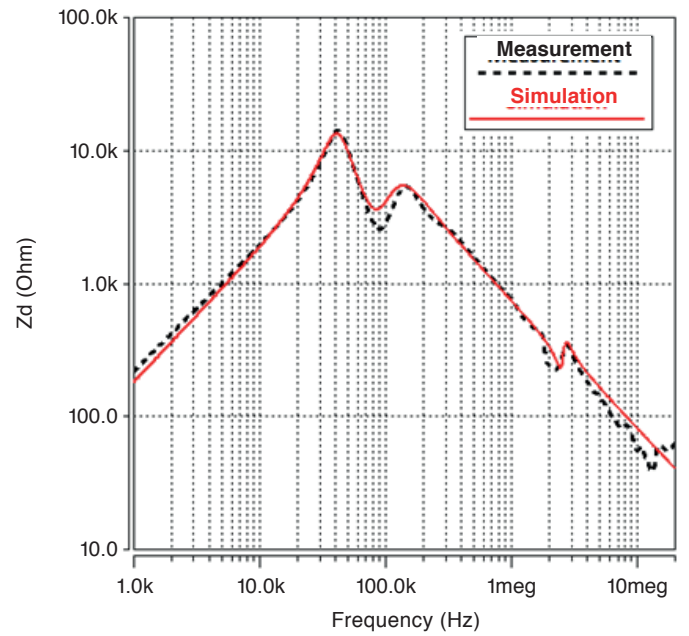

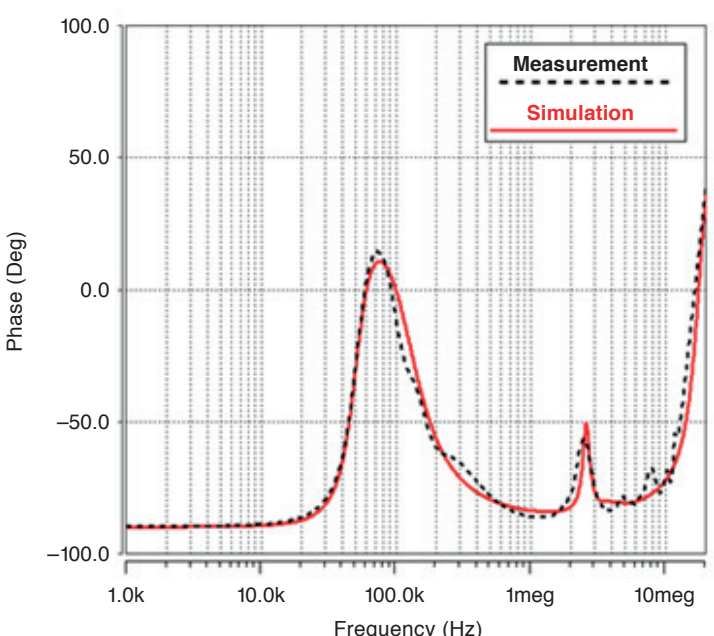

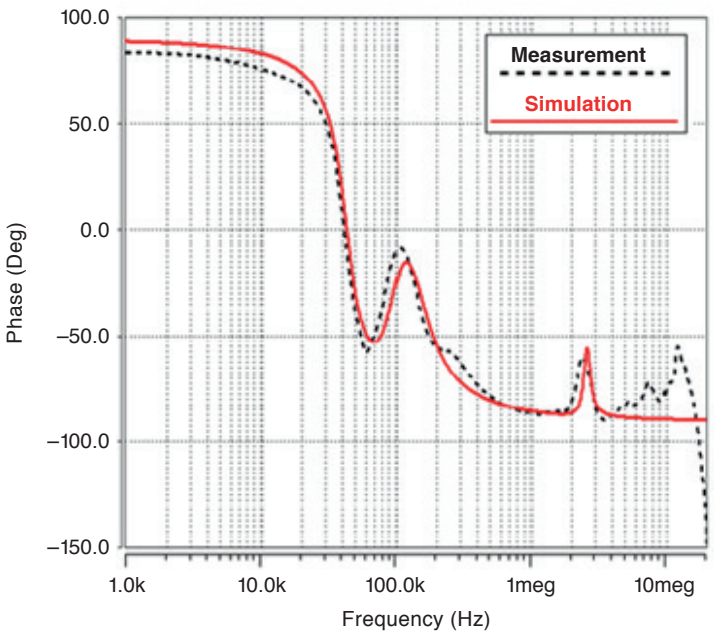

Fig. 6. Measurement and simulation of the $7.5 \mathrm{~kW}$ induction machine: a) common-mode impedance, b) differential-mode impedance

impedance characteristics in the indicated sections in Figs. 2 and 3 is confirmed by the measurements. Resonance frequencies and their corresponding values of impedance $\mathrm{Z}_{\mathrm{c}}$ and $\mathrm{Z}_{\mathrm{d}}$ from the simulation are also close to measured results. It should be noted that good coherence between the simulation and experimental results is observed for frequencies up to $10 \mathrm{MHz}$. At a higher range of frequency, an influence of additional components, which are identified for each machine separately, is visible. It causes significant differences of analyzed impedance characteristics, even between machines of the same type [14]. Hence, the proposed

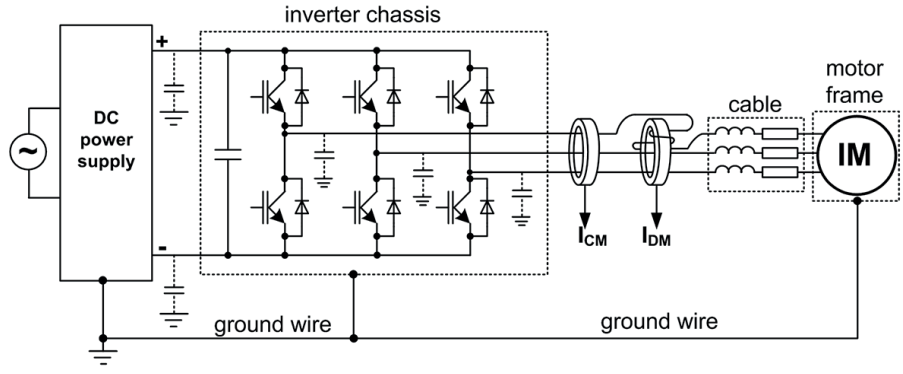

Fig. 7. Laboratory setup for experimental tests model can be used as a unified model for any IM at a frequency range of analysis lower than $10 \mathrm{MHz}$. In order to increase the frequency range, the topology of the model must be extended.

In the following experiment, EMI common-mode and differential-mode current spectra of inverter-fed IM drives were compared. Disturbance currents were measured according to the method presented in [17] using a laboratory setup as shown in Fig. 7. The measuring equipment consisted of a Tektronix DPO $4034100 \mathrm{MHz}$ oscilloscope and a TCP2020 current probe (20 $\mathrm{A}_{\mathrm{RMS}}, 100 \mathrm{~A}_{\text {Peak }} / \mathrm{DC} 50 \mathrm{MHz}$ ).

The simulation test circuit was composed of a model of the inverter and a model of the induction machine (Fig. 8). Sinusoidal voltage sources were connected in series between models of the induction machine and of the inverter to simulate the impact of the rotational electromotive force of the machine. The model of the inverter consisted of wideband models of IGBT modules $[10,22]$ and simplified models of paths, conductors, and passive elements (e.g. the skin effect was not considered). The parasitic capacitances were considered in the most important nodes, e.g. output terminals of power supply units, or input and output terminals of the inverter. Values of parasitic components were obtained using a Keysight E4990A impedance analyzer. 


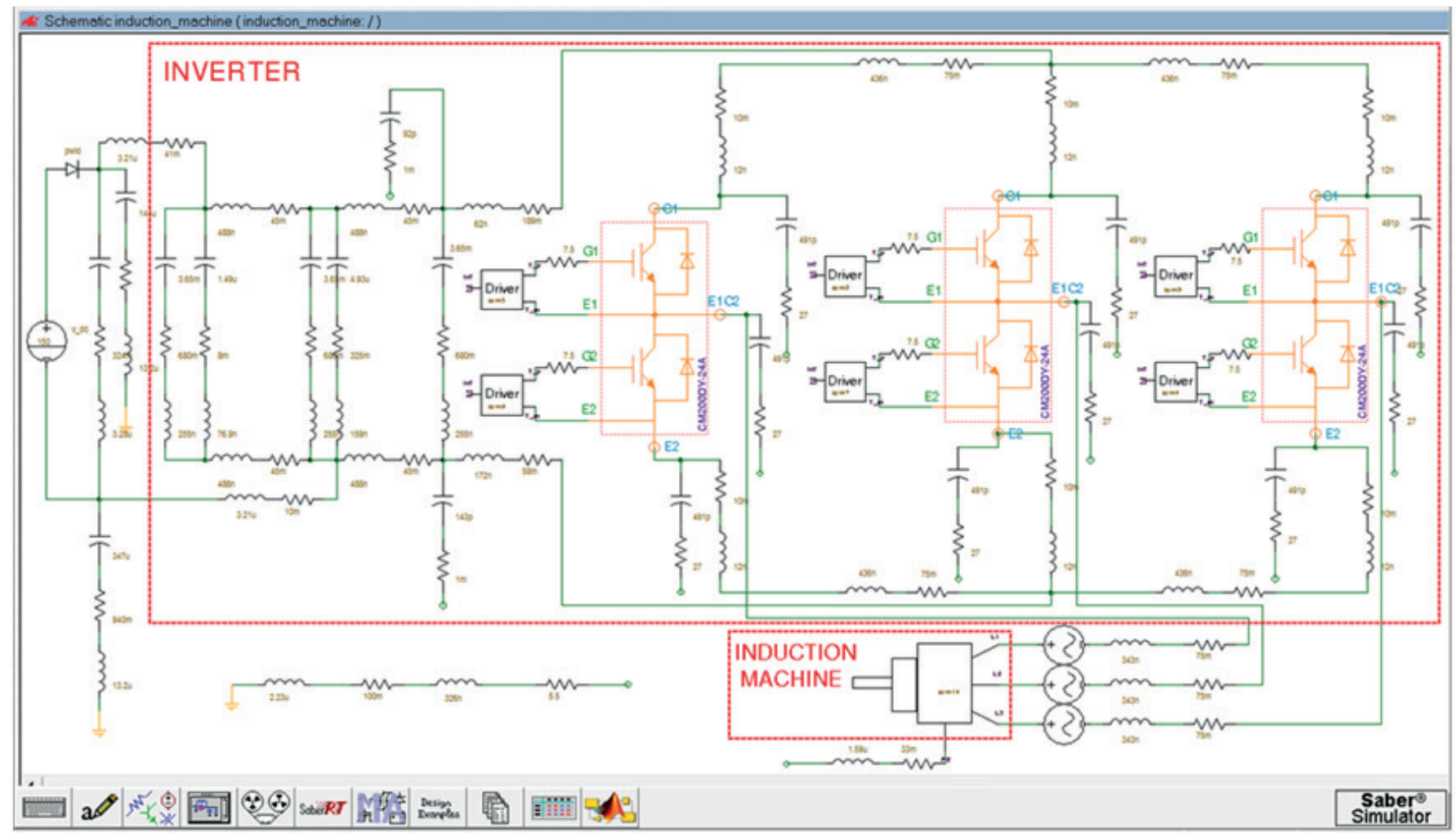

Fig. 8. Saber Sketch scheme of test bench

A good agreement between simulated and experimental spectra of the common-mode current $\mathrm{I}_{\mathrm{CM}}$ is reported in Fig. 9. The shape of the simulated spectrum as well as its main levels and most important resonant frequencies are also distinguishable in experimental results, especially for frequencies up to $1 \mathrm{MHz}$. At a higher range of frequency, significant peaks in experimental $\mathrm{I}_{\mathrm{CM}}$ spectrum at $3 \mathrm{MHz}$ and $6.8 \mathrm{MHz}$ are also noted for the simulated results.
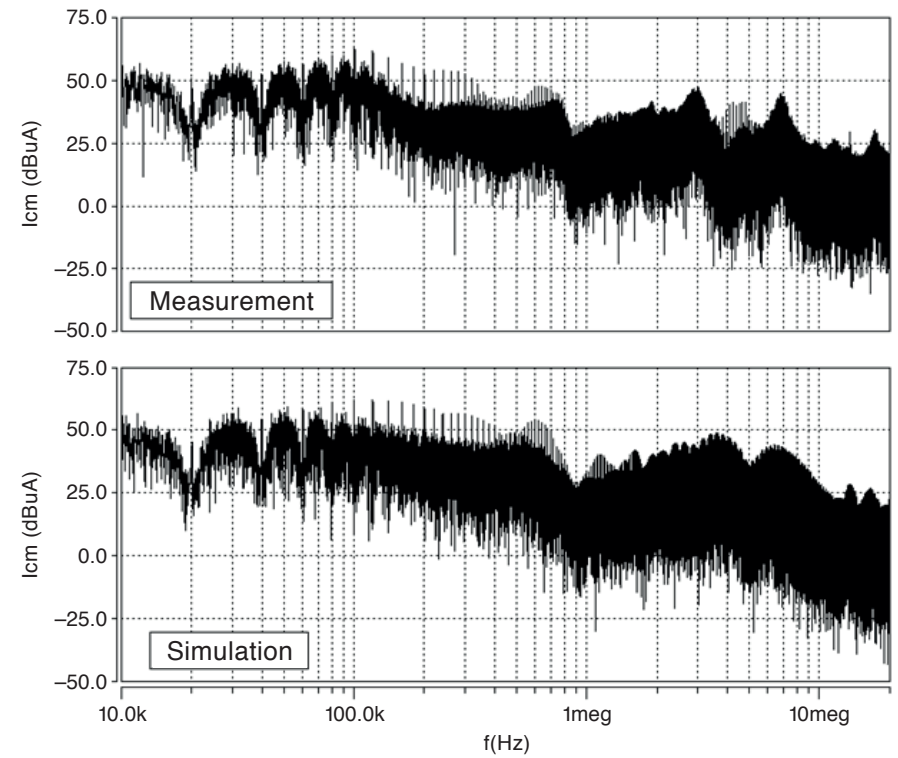

Fig. 9. Spectra of the common mode current ICM measured between $1.5 \mathrm{~kW}$ induction machine and inverter; measurement and simulation
However, the shape of the simulated spectrum around these peaks is fuzzy and peak frequencies are shifted about $0.5 \mathrm{MHz}$ relative to the experimental values. Nevertheless, the maximum values of peaks in simulated $\mathrm{I}_{\mathrm{CM}}$ spectrum are close to the results of the measurement. In the case of the differential-mode current $\mathrm{I}_{\mathrm{DM}}$ spectrum, a satisfactory correlation between simulated and measured results is observed for frequencies lower than $600 \mathrm{kHz}$ (Fig. 10).
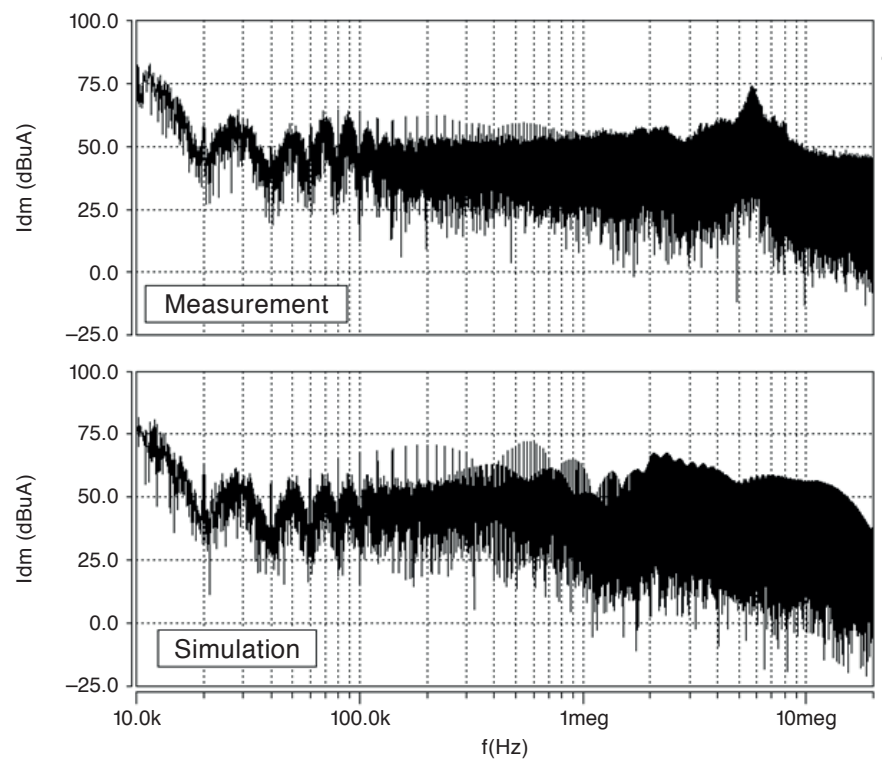

Fig. 10. Spectra of the differential mode current IDM measured between $7.5 \mathrm{~kW}$ induction machine and inverter; measurement and simulation 
A significant peak around $5 \mathrm{MHz}$ is clearly distinguishable in the experimental spectrum of the differential mode current, but it is not reported for the simulated results. However, the levels of the simulated spectra are close to those measured. It should be noted that the impact of other parasitic components causes a slight difference between simulated and measured results for frequencies higher than $1 \mathrm{MHz}$.

\section{Conclusions}

In this paper, the wideband behavioral model of IM has been introduced. The model has been implemented and evaluated in the SABER circuit simulator for induction machines of $1.5 \mathrm{~kW}$ and $7.5 \mathrm{~kW}$. The desired accuracy has been validated by simulation and experimental results and is comparable with other, more complex solutions. The proposed model can be applied to other simulators without significant modifications. In relation to compared solutions, the presented model is less complicated and its analytical description is simpler, which also results from the elimination of mutual inductances between the windings of different phases. It may have an important role when advanced topologies of converters are simulated. Then, a level of computational loads incorporated by wideband models affects the numerical stability and the total time of calculation.

Model parameter extraction method is based on the measurable impedance characteristics and available optimization algorithms. This model can be effectively applied for simulation and assessment of IM-conducted EMI propagation in the form of common- and differential-mode currents.

\section{REFERENCES}

[1] S. Bartos, I. Dolezel, J. Necesany, J. Skramlik, and V. Valouch, "Electromagnetic interferences in inverter-fed induction motor drives", International Conference on Renewable Energies and Power Quality, (2008).

[2] H. Miloudi, A. Bendaoud, K. Mendaz, M. Benhadjla, A. Gourbi, and M. Brahami, "Modeling of differential-mode and common-mode characteristics for EMI/EMC analysis applied to a high-frequency induction motor", IV International Symposium on Power Quality SICEL-2007 19, (2007).

[3] R. Smoleński, "Selected conducted electromagnetic interference issues in distributed power systems", Bull. Pol. Ac.: Tech. 57 (4), 383-393 (2009).

[4] R. Smoleński, M. Jarnut, G. Benysek, and A. Kempski, "CM voltage compensation in $\mathrm{AC} / \mathrm{DC} / \mathrm{AC}$ interfaces for smart grids", Bull. Pol. Ac.: Tech. 59 (4), 513-523 (2011).

[5] A. Roc'h, Behavioural Models for Common-Mode EMI Filters, PhD Thesis, University of Twente, Enschede, 2012.

[6] J. Itoh, T. Araki, and K. Orikawa, "Experimental verification of an EMC filter used for PWM inverter with wide band-gap devices", International Power Electronics Conference IPEC, Hiroshima, Japan, 1925-1932 (2014).
[7] B. Revol, J. Roudet, J.L. Schanen, and P. Loizelet, "EMI study of a three phase inverter-fed motor drives", 39th IAS Annual Meeting Industry Applications Conference 4, 2657-2664 (2004).

[8] M. Turzynski and W.J. Kulesza, "A simplified behavioral mosfet model based on parameters extraction for circuit simulations", IEEE Trans. on Power Electronics 31 (4), 3096-3105 (2016).

[9] N. Bondarenko, Electromagnetic Compatibility in Power Inverter Design, PhD Thesis, Missouri University of Science and Technology, 2015.

[10] P. Musznicki, M. Turzyński, and P.J. Chrzan, "Accurate modeling of quasi-resonant inverter fed IM drive", 39th Annual Conference of the IEEE Industrial-Electronics-Society (IECON), 376-381 (2013).

[11] E. Zhong and T.A. Lipo, "Improvements in EMC performance of inverter-fed motor drives", IEEE Trans. on Industry Applications 31 (6), 1247-1256 (1995).

[12] A. Boglietti and E. Carpaneto, "Induction motor high frequency model", Thirty-Fourth IAS IEEE Industry Applications Conference 3, 1551-1558 (1999).

[13] F. Della Torre, S. Leva, and A.P. Morando, "Three-phase distributed constants model of induction machines for EMC and surge propagation studies", COMPEL - International Journal for Computation and Mathematics in Electrical and Electronic Engineering 27 (4), 770-779 (2008).

[14] S.-P. Weber, E. Hoene, S. Guttowski, W. John, and H. Reichl, "Modeling induction machines for EMC-Analysis", IEEE 35th Annual Power Electronics Specialists Conference PESC 04 1, 94-98 (2004).

[15] G. Grandi, D. Casadei, and U. Reggiani, "Equivalent circuit of mush wound $\mathrm{AC}$ windings for high frequency analysis", IEEE International Symposium on Industrial Electronics 1, Guimaraes, Portugal, 201-206 (1997).

[16] G. Grandi, D. Casadei, and A. Massarini, "High frequency lumped parameter model for AC motor windings", European Conference on Power Electronics and Applications, Trondheim, Norway, (1997).

[17] G. Grandi, D. Casadei, and U. Reggiani, "Analysis of commonand differential-mode HF current components in PWM inverter-fed AC motors", 29th Annual IEEE Power Electronics Specialists Conference 2, 1146-1151 (1998).

[18] G. Grandi, D. Casadei, and U. Reggiani, "Common- and differential-mode HF current components in AC motors supplied by voltage source inverters", IEEE Trans. Power Electron. 19 (1), 16-24 (2004).

[19] S. Kim and D.P. Neikirk, "Compact equivalent circuit model for the skin effect", IEEE MTT-S International Microwave Symposium Digest 3, 1815-1818 (1996).

[20] Find Minimum of Unconstrained Multivariable Function Using Derivative-Free Method-MATLAB fminsearch, http://www.mathworks.com/help/matlab/ref/fminsearch.html, (2016).

[21] GNU Octave: Minimizers, https://www.gnu.org/software/octave/ doc/v4.0.1/Minimizers.html, (2016).

[22] M Turzyński, Behavioral Modeling of IGBT Transistors for Simulation of Power Electronics, Wydawnictwo Politechniki Gdańskiej, Gdańsk, 2012, [in Polish]. 